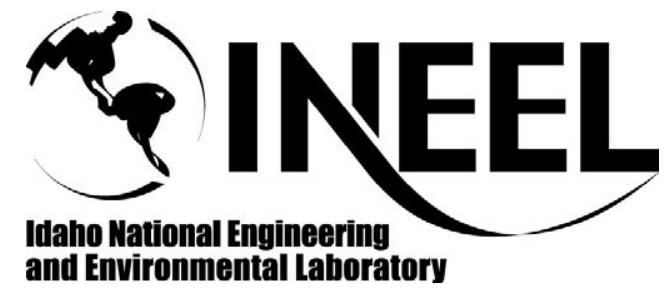

INEEL/CON-02-00017

PREPRINT

Generation-IV Multi-Application Small Light Water Reactor (MASLWR)

April 14, 2002

\title{
Tenth International Conference On Nuclear Energy
}

This is a preprint of a paper intended for publication in a journal or proceedings. Since changes may be made before publication, this preprint should not be cited or reproduced without permission of the author.

This document was prepared as a account of work sponsored by an agency of the United States Government. Neither the United States Government nor any agency thereof, or any of their employees, makes any warranty, expressed or implied, or assumes any legal liability or responsibility for any third party's use, or the results of such use, of any information, apparatus, product or process disclosed in this report, or represents that its use by such third party would not infringe privately owned rights. The views expressed in this paper are not necessarily those of the U.S. Government or the sponsoring agency. 


\section{GENERATION-IV MULTI-APPLICATION SMALL LIGHT WATER REACTOR (MASLWR)}

\author{
S. Michael Modro - INEEL \\ Kevan Weaver - INEEL \\ John Groome - OSU
}

Pierre Babka - Nexant

\author{
James Fisher - INEEL \\ Jose Reyes - OSU \\ Gary Wilson ${ }^{1}$
}

\section{ABSTRACT}

The Idaho National Engineering and Environmental Laboratory (INEEL), Nexant Inc. and the Oregon State University (OSU) have developed a Multi-Application Small Light Water Reactor (MASLWR) concept. The MASLWR is a small, safe and economic natural circulation pressurized light water reactor.

MASLWR reactor module consists of an integral reactor/steam generator located in a steel cylindrical containment. The entire module is to be entirely shop fabricated and transported to site on most railways or roads. Two or more modules are located in a reactor building, each being submersed in a common, below grade cavity filled with water. For the most severe postulated accident, the volume of water in the cavity provides a passive ultimate heat sink for 3 or more days allowing the restoration of lost normal active heat removal systems. MASLWR thermal power of a single module is 150 MWt, primary system pressure $10.5 \mathrm{MPa}$, steam pressure 1.52 $\mathrm{MPa}$ and the net electrical output is $35-50 \mathrm{MWe}$.

\section{INTRODUCTION}

By 2030 the demand for energy and electricity is projected to rise by about $50 \%$ above today's demand, and be nearly double by 2050 . Growing concerns for the environment will favor energy sources that can satisfy the need for electricity and other energy-intensive products on a sustainable basis, with minimal environmental impact, accelerated deployment, and competitive economics. In response to these needs under the Nuclear Energy Research Initiative (NERI) program the Idaho National Engineering and Environmental Laboratory (INEEL), Nexant Inc. and the Oregon State University (OSU) have developed a Multi-Application Small Light Water Reactor (MASLWR) concept. follows:

The strategic goals driving the MASLWR design are as

- Minimize development time (Goal of five years or less)

- Utilize existing institutional licensing and safety experience

- Utilize existing manufacturing capabilities for components and fuel

- Design to maximize modularization

- Minimize deployment time (Goal of three years or less for first plant)

- Maximize use of off-the-shelf hardware (turbines,

- I\&C, etc.)

- Standardized design

- Design certification before construction (Construction goal of two years)

- Optimize operations

- Design for 60 year reactor module life-cycle

- Maximize plant availability factor

- Design for five year turbine and core replacement

- Design to pull and replace total reactor module (turbine/core replacement, etc.)

- Use off-site assembly, disassembly of each reactor module

- Phased construction (Add new pairs of reactor modules as need develops)

\footnotetext{
${ }^{1}$ Retired, formerly with INEEL
} 
- Minimize capital and operational costs (Goal is busbar costs at $3.5 \mathrm{c} / \mathrm{kWh}$ or less)

The MASLWR concept was developed in an evolutionary process exploring the economic limits and potential for smallpressurized natural circulation light water reactors. Initially, a concept of $300 \mathrm{MWe}$ - the upper end of power range suggested for small reactors by the NERI - was considered. Cost analyses showed that a natural circulation PWR at this power level is not economical because the capital investments required for such a plant were too high. A natural circulation plant of this size with passive safety features required a very large containment. The primary system components were also large and the required auxiliary and support systems were similar to a 600 MWe plant. Therefore, the capital investment required for this plant would be close to those of a $600 \mathrm{MWe}$ plant at only a half of electrical output. The only way to reduce capital cost while maintaining a natural circulation PWR system was to reduce power and significantly simplify the design.

\section{MASLWR CONCEPT}

The MASLWR is a small, safe and economic natural circulation light water reactor (see Figure 1 and Table 1) that is being developed with the primary goal of electric power generation, but including the flexibility to be used for process heat applications such as water desalination or district heating with deployment in a variety of locations. The reactor concept is flexible enough for early deployment (2010-2015) using modern LWR oxide fuels, in a later phase using UraniumThorium fuels and eventually new advanced fuels, such as metal fuels, that promise additional safety features, increased efficiency, and more economic fuel cycle. This approach to gradual development of a nuclear power system, not practical for large high power systems, is possible only for small size modular reactors such as the MASLWR, because of simplicity of the reactor design, low cost of the module, and simplified licensing procedures based on prototype testing.

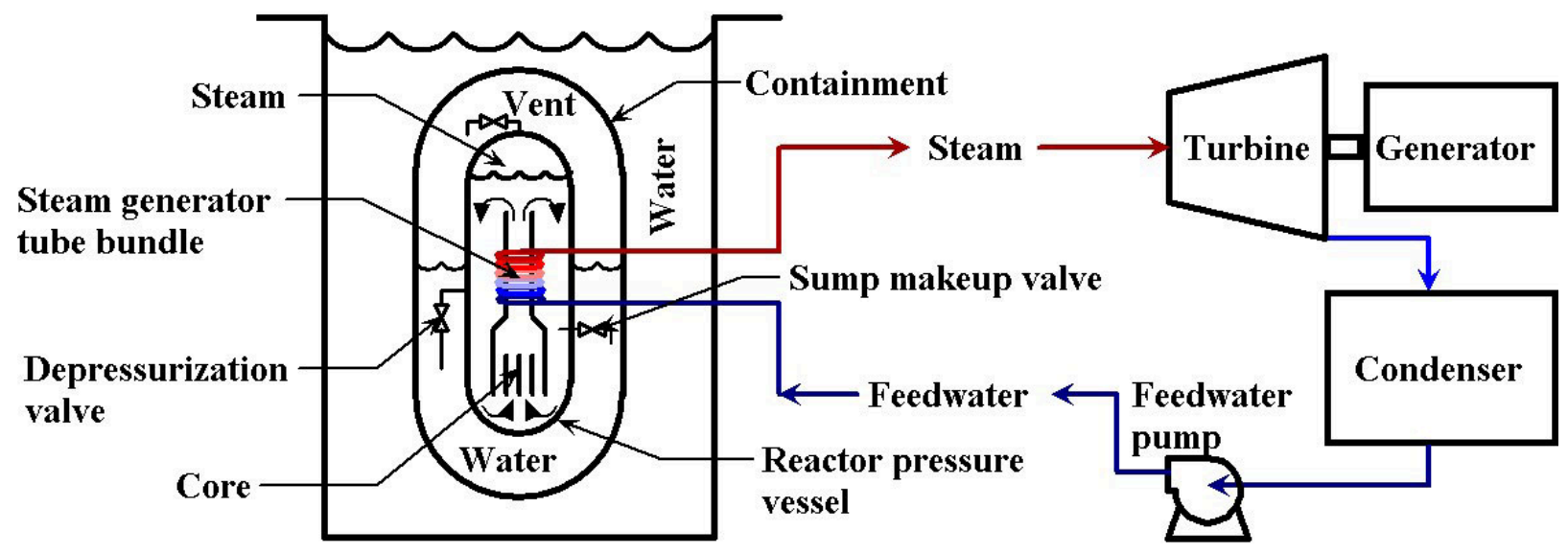

Figure 1. MASLWR baseline design concept

Table 1. Key design features

$\begin{array}{cc}\text { Thermal Power } & 150-200 \mathrm{MWt} \\ \text { - Primary system pressure } & 7.6 \mathrm{MPa}(1100 \mathrm{psia})\end{array}$
- Net Electrical Output
- Steam pressure

The MASLWR reactor module consists of an integral reactor/steam generator located in a steel cylindrical containment. This containment is partially filled with water to provide pressure suppression and liquid makeup capability in the event of a loss of fluid from the primary system. The entire module is $4.3 \mathrm{~m}(14 \mathrm{ft})$ diameter and $18.3 \mathrm{~m}(60 \mathrm{ft})$ long, which allows it to be entirely shop fabricated and transported to site on most railways or roads. Two or more modules are located in a reactor building, each being submersed in a common, below grade cavity filled with water (Figure 2). Cooling of the containment during normal and abnormal conditions is accomplished by heat conduction through the containment steel walls to the cavity water. Heat from the cavity water is removed through a closed loop 
circulating system and rejected into the atmosphere in a cooling tower. For the most severe postulated accident, the volume of water in the cavity provides a passive ultimate heat sink for well over 3 days to allow the restoration of active heat removal systems.

\section{REACTOR SYSTEMS}

The NSSS design is a "self-contained" assembly of reactor core and heat exchanger (steam generator) within a single pressure vessel surrounded by containment (Figures 1 and 3). The nuclear core is located in the lower part of the vessel, with the steam generator above it. To effectively use natural circulation, the core is connected directly to the space above the heat exchanger via a large-diameter tube, or riser, which is an upper extension of the core barrel. The primary liquid flow path is upward through the riser, then downward around the heat exchanger tubes with return to the bottom of the core via an annular space. The use of natural circulation reduces the number of active components and simplifies the configuration of NSSS.
In this stage of MASLWR development, the core and fuel (with the exception of the enrichment) design are assumed to be similar to present pressurized water reactors. The core consists of $24,17 \times 17$ PWR assemblies, with an active fuel height of approximately $1 \mathrm{~m}(3.3 \mathrm{ft}$.). The overall height to diameter (H/D) ratio for the core is approximately 1 . The fuel exists in cylindrical pins with a cladding outer diameter of 9.5 $\mathrm{mm}$ (0.37 in.), and a pitch-to-diameter ratio (P/D) of 1.33 using a square pitch. The fuel pellets are UO2, enriched to $8 \%$ U-235. This first step design allows for 5 years between refuelings, based on a single batch, once through core.

Although the use of current LWR technology is employed in the current design, further enhancements to better meet Generation IV goals will be explored; particularly the efficient use of uranium (fuel) resources by optimizing the core design, fuel material, and fuel cycle. This will include the use of burnable poisons, the use of alternative fuels like thorium, and optimization of reactivity characteristics that would further enhance the safety of this concept.

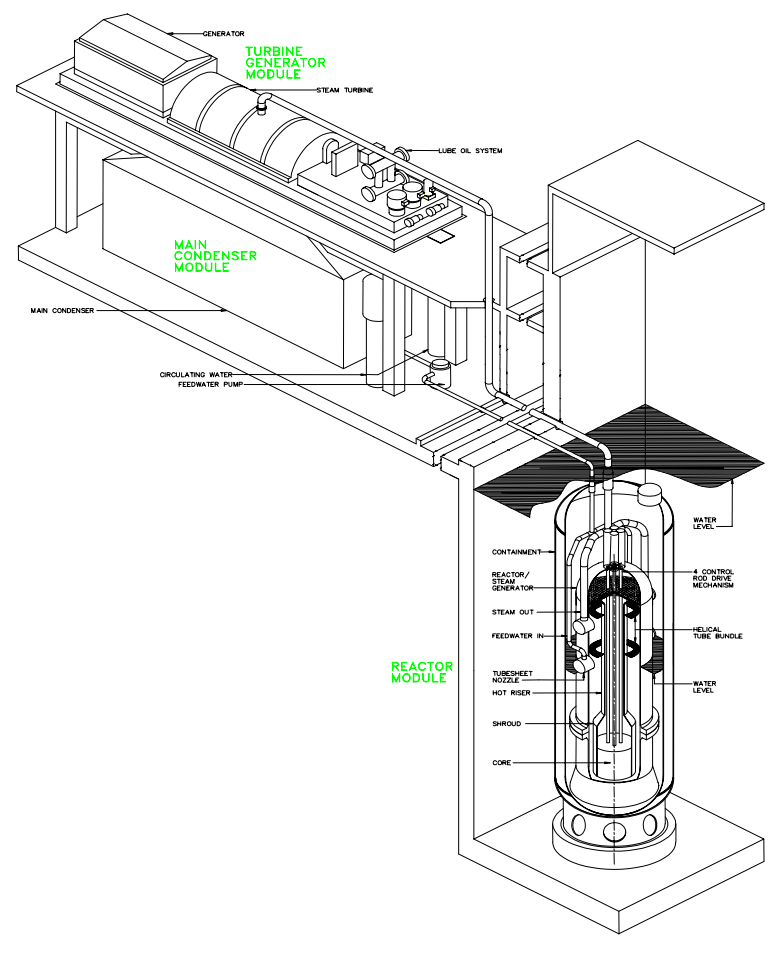

Figure 2. Isometric representation of single power module

The steam generator is a helical-tube, once-through heat exchanger, located in a common vessel with the reactor. The heat exchanger consists of approximately 1000 tubes, arranged in an upwardly spiraling pattern. Cold feedwater 
enters the tubes at the bottom, and saturated steam is collected at the top. Heat generated in the core raises the temperature of the primary coolant from $492 \mathrm{~K}(426 \mathrm{~F})$ to $544 \mathrm{~K}(520 \mathrm{~F})$. This heat is removed while the coolant is flowing down across the steam generator tubes. The resulting steam formed inside the tubes is expanded in a turbine generator to produce power.

\section{CONTAINMENT AND SAFETY SYSTEMS}

Safety performance of the MASLWR unit is assured through a typical ALWR fast shutdown system, two independent automatic depressurization system (ADS) trains and heat transfer from the containment. In emergencies the reactor is scrammed and the ADS activated. The pressures in the primary system and the containment are quickly equalized (the containment is designed for $1.72 \mathrm{MPa}, 250 \mathrm{psi}$ ) and the ADS flow paths assure natural circulation of coolant between the containment and the primary system, therby providing cooling to the core. The containment itself is completely submerged in a large pool of water, which serves as the ultimate heat sink for cooling the reactor. In the event of an accident, steam condensation on the walls of the containment provides the required heat rejection. Figure 1 illustrates the concept.

The performance of the design has been verified and optimized during accident studies. The objectives of these studies were:

- Demonstrate adequate cooling of the reactor core

- Demonstrate the mechanism and adequacy of heat removal to the ultimate heat sink

- Determine the size and location requirements for the automatic depressurization and sump makeup systems.

The important conclusions regarding the performance of these systems are the following.

- The reactor core can be provided with a stable cooling source adequate to remove decay heat without significant cladding heat up under all credible scenarios.

- During accident conditions a recirculation flow path is established between the vessel and the containment via the ADS and sump makeup systems. This recirculation path provides sufficient capability for removal of decay heat from the vessel.

- The heat rejected through the containment wall to the surrounding pool of water exceeds the amount of decay heat produced by the reactor core.

\section{BALANCE OF PLANT}

Each reactor module has an associated turbine generator and condenser making an independent power unit. Because of the relatively low steam pressure, the turbine consists of only a low-pressure section. The heat removed from the condenser by the circulating water is rejected to the atmosphere in a forced-drafted cooling tower. Because the module is relatively small, a novel approach is used to perform refueling and maintenance activities. The entire module is removed and transported under water to an adjacent refueling/maintenance facility. While the removed module is refueled and maintained, it is immediately replaced with a spare module. This results in a short down time of the reactor. The refueling and maintenance activities are entirely automated. After decay, spent fuel is shipped off site for disposal/reprocessing. New fuel is brought to the site.

A MASLWR plant may be a single module or consist of multiple reactor modules (Figure 2). The operation of the plant is entirely automated during both normal and abnormal conditions. Following an accident no operator action is required which prevents any human errors. For a multimodule deployment there is a main control room and remote shutdown room serving all reactors. The multi-module plant is intended to be operated as a baseload plant. Each reactor is to be operated at full load. Should the demand be reduced, some of the reactors can be shutdown and kept on hot standby. The plant can be deployed sequentially depending on electricity demand. As little as two reactor modules can be initially installed. As the demand for power increases, additional modules are added as needed.

\section{EXPERIMENTAL PROGRAM}

A 1/3 height scale, 1/254.7 volume scale integral system test facility is being built at Oregon State University to assess the performance of the MASLWR concept. The primary loop test section is planned to be operational in March 2002. The focus of the initial test series is to a) assess the thermal hydraulic stability of the primary loop under full power natural circulation conditions and b) to develop start-up and operational procedures for the new design. Several preliminary design-basis accident scenarios will also be simulated in test facility.

The experimental facility models all of the important design features of MASLWR and takes significant advantage of the existing support facilities for the APEX facility ${ }^{2}$. The MASLWR integral experiment facility (Figure 3) consists of a $36 \mathrm{~cm}$ (14 in) diameter pressure vessel that houses 90 electric heater rods, a vertical riser section, 5 helical steam generator tubes and a downcomer. The facility will be operated at full MASLWR pressure and full temperature conditions. It will be capable of simulating all of the safety

2 The APEX facility is an integral test system simulating the AP600 reactor system. 
and operations related thermal hydraulic behavior of interest

to the design assessment program.

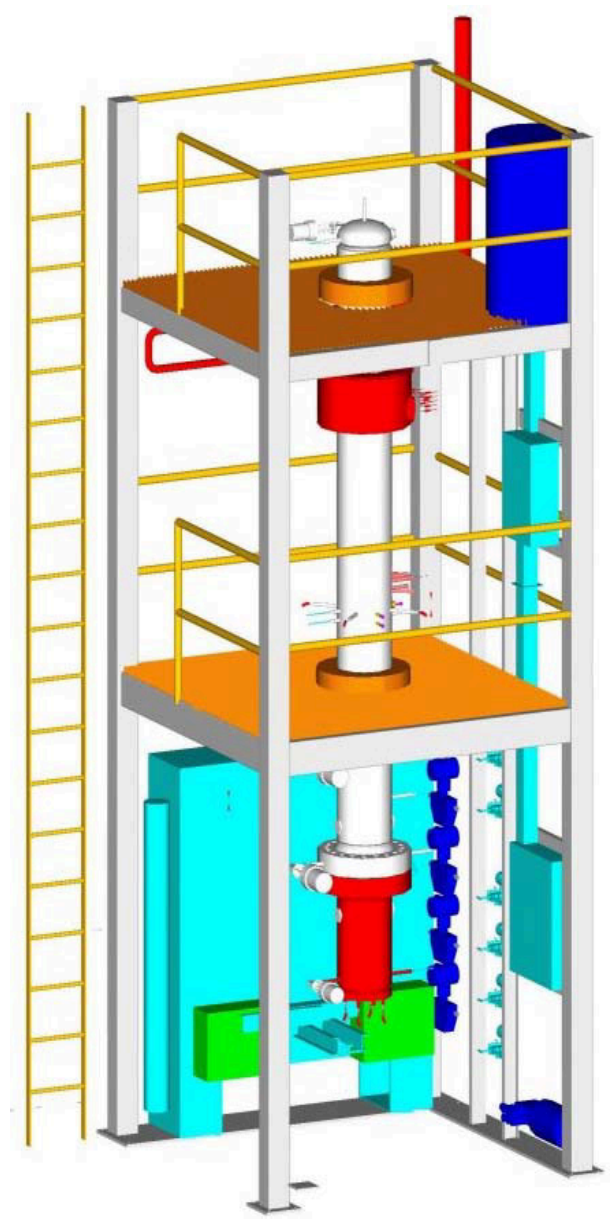

Figure 3. OSU MASLWR experimental facility

\section{SAFETY ANALYSES}

Redundant sets of 3-inch upper containment automatic depressurization system (ADS) vent lines, submerged 4-inch ADS blowdown lines, and 4-inch sump makeup lines are provided to ensure adequate core cooling and decay heat removal and to prevent containment overpressure. Simulations of postulated loss-of-coolant accident and other scenarios determined the required configuration and sizes of these lines. A variety of these simulations has been performed to date, including:

- Nozzle breaks at each vessel piping penetration

- Inadvertent opening of a submerged ADS blowdown line valve

- Main steam line pipe rupture and loss-of-main feedwater
- Uncontrolled withdrawal of reactor control rod cluster assemblies

- Reactor control rod ejection

The major results of two of the more interesting scenarios, the nozzle breaks of the submerged ADS blowdown line and of the upper containment ADS vent line, is summarized below.

Figure 4 shows the system responses of vessel collapsed liquid level and fuel cladding surface temperature during a postulated break of a submerged ADS blowdown line nozzle. This scenario represents the most severe break location for rapid depletion of vessel inventory and core uncovery. As shown, the configuration provides adequate coolant makeup into the vessel to prevent core dryout and fuel cladding 
temperature excursions, and to cause the system to achieve a stable end state.

Figure 5 shows the system energy balance and primary vessel and containment pressure responses for the upper containment ADS vent line nozzle break, which results in the most severe containment pressure transient response. The break of this nozzle results in a rapid containment pressure increase that is mitigated by the actuation of the submerged ADS blowdown system, which vents the primary system into spargers in the containment located below the waterline, thereby maintaining containment pressure within acceptable limits. As shown, the heat transfer through the containment outer wall to the surrounding liquid pool is adequate to remove the decay power produced by the core.

The results of the simulations of the postulated loss-of-coolant accident and other scenarios show that the reactor core will have a stable source of cooling water that is adequate to remove decay heat without significant cladding heatup for all credible scenarios. The automatic depressurization systems serve to vent the primary system during postulated accidents while preventing excessive pressure within the containment. The heat rejection capacity of the system via the containment wall to the surrounding pool of water is sufficient to provide short- and long-term cooling for the reactor core

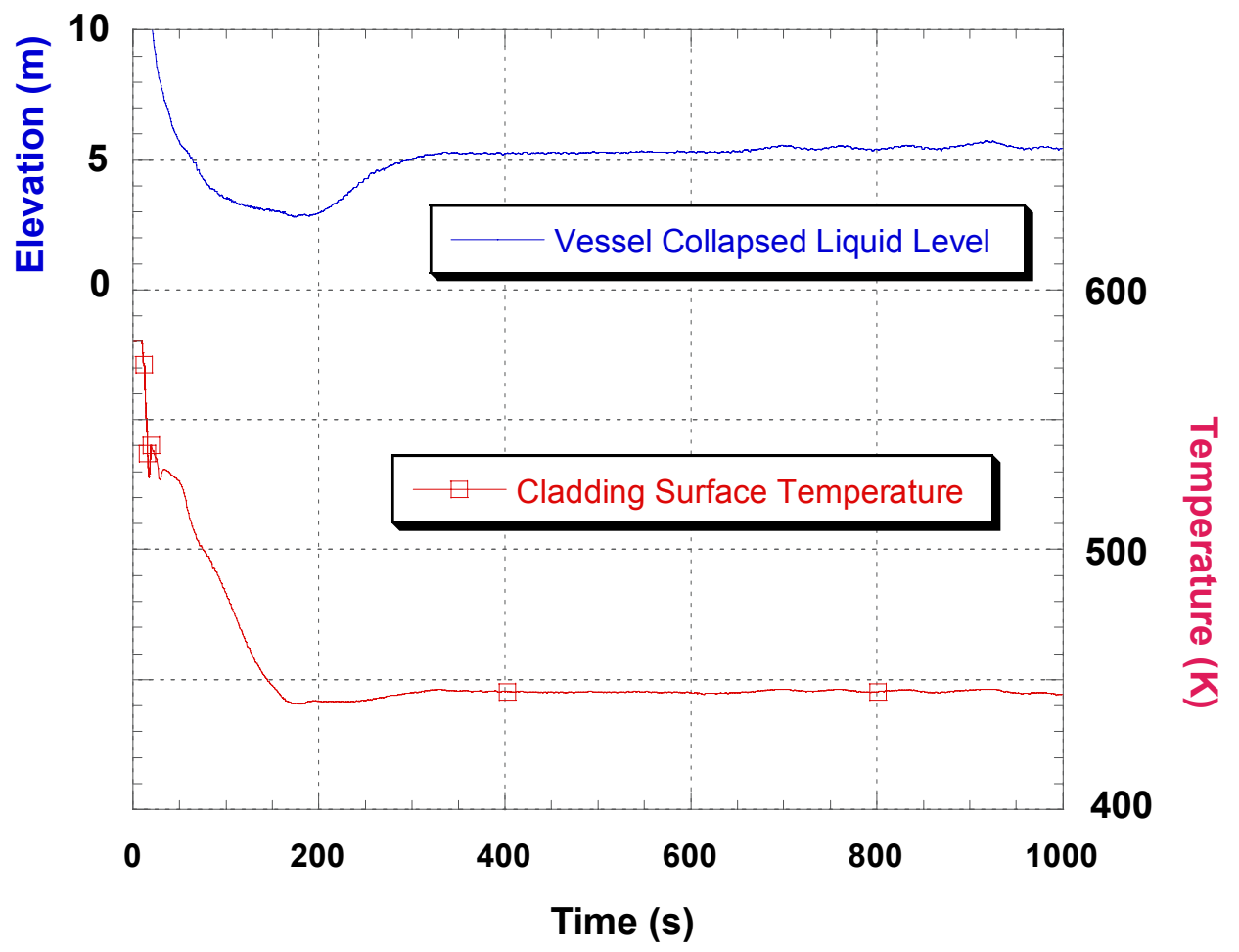

Figure 4. Primary vessel collapsed liquid level and cladding surface temperature responses during submerged ADS blowdown line nozzle break scenario. 


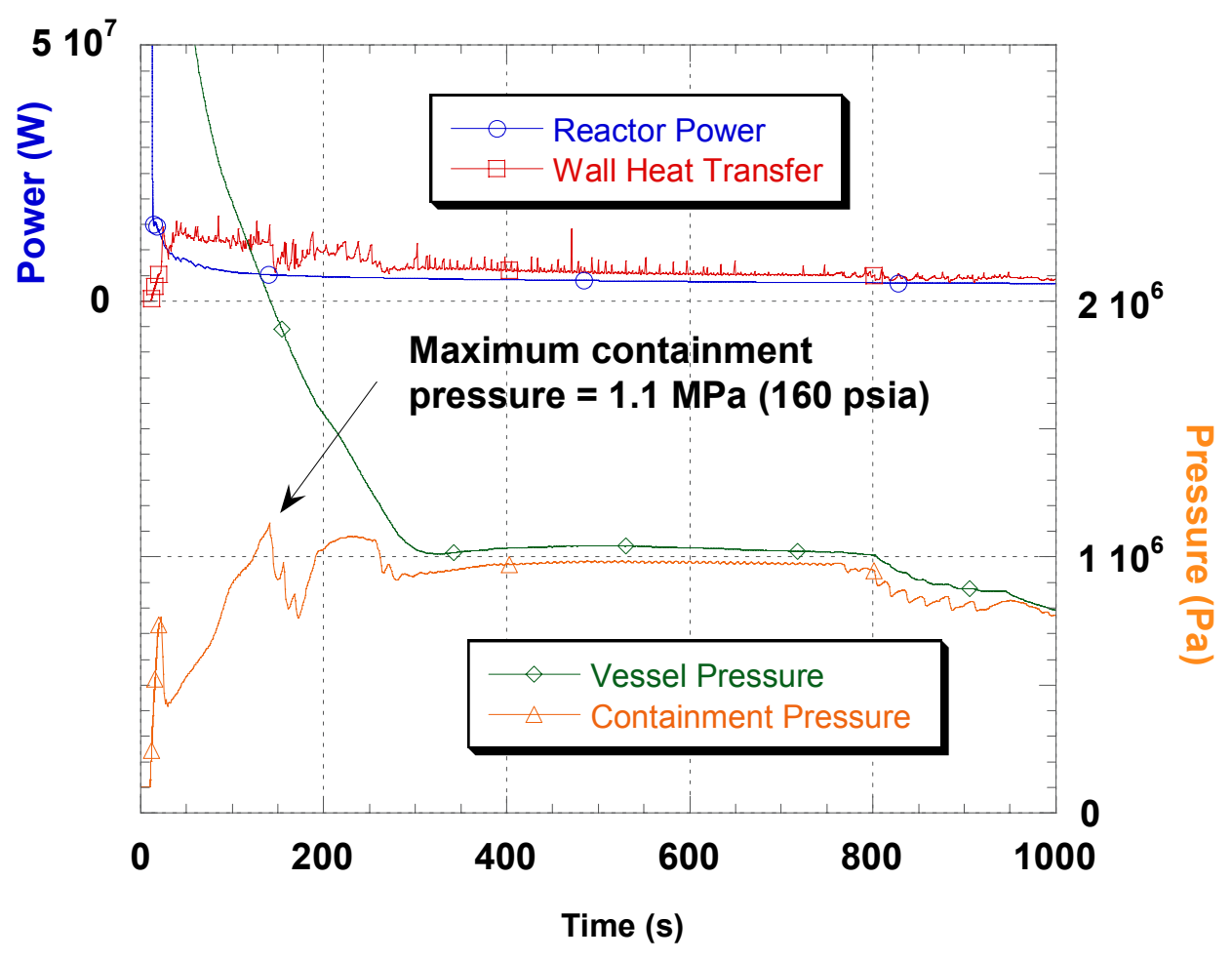

Figure 5. System energy balance and pressure responses during upper containment ADS vent line nozzle break scenario.

\section{CONCLUSIONS}

The MASLWR concept was developed exploring economic limits and potential for small-pressurized natural circulation light water reactor. The design work and safety analysis performed so far indicate that the MASLWR concept can be an economic, safe and easy to deploy reactor design that utilizes extensively existing licensing and industrial experience. The concept development continues and the future work will include integral system experiments to verify analytical tools used and to evaluate MASLWR operational and safety performance.

\section{ACKNOWLEDGMENTS}

This work was supported by the Department of Energy (DOE) under DOE Idaho operations Office Contract

DE-AC07-99ID13727 